\title{
COMPOSIÇÃO QUÍMICA DA CANA-DE-AÇUCAR (Saccharum SPP.) E DAS SILAGENS COM DIFERENTES ADITIVOS EM DUAS IDADES DE CORTE ${ }^{1}$
}

\author{
Chemical composition of sugar cane (Saccharum SPP.) and of the silages with \\ different additives at two cutting ages
}

\author{
Roberto Valadares Santos ${ }^{2}$, Antônio Ricardo Evangelista ${ }^{3}$, José Cardoso Pinto ${ }^{3}$, \\ Cristovão Colombo de Carvalho Couto Filho ${ }^{4}$, Ronan Magalhães de Souza ${ }^{5}$
}

\begin{abstract}
RESUMO
Objetivou-se com este estudo avaliar a composição química da forragem e da silagem de cana-de-açúcar em duas idades de corte com diferentes aditivos. Os tratamentos foram arranjados em um delineamento inteiramente casualizado, com três repetições, em esquema fatorial 2 × 9, sendo duas idades de corte (11 e 24 meses) e nove formas de uso (cana picada acrescida de $1 \%$ da mistura uréia e sulfato de amônio, cana in natura e ensilada sem aditivo, cana in natura e ensilada com $1 \%$ de uréia, cana in natura e ensilada com de $8 \%$ de MDPS e cana in natura e ensilada com de 0,5\% de sal mineral). A concentração de MS da cana-de-açúcar nos 11 meses foi em média , 25,9\% inferior a de 24 meses de idade. Os valores de $\mathrm{pH}$ não variaram com as idades de corte, porém, diferiram entre os tratamentos silagem e cana in natura. A cana in natura adicionada com $1 \%$ da mistura uréia + sulfato de amônio resultou nos melhores valores bromatológicos, o mesmo ocorrendo com a cana ensilada com uréia, sendo portanto mais conveniente ensilá-la do que deixá-la no campo por mais um período de cultivo. O material ensilado apresentou teores mais elevados de PB, FDN e FDA.
\end{abstract}

Termos para indexação: Idade de corte, uréia, sulfato de amônio, mineral.

\begin{abstract}
It was aimed by this study to evaluate the chemical composition of the sugar cane forage and silage at two cutting ages with different additives. The treatments were arranged in a completely randomized design with three replicates in a $2 \times 9$ factorial scheme, their being two cutting ages (11 and 24 months) and nine forms of use (chopped cane added of $1 \%$ of the mixture urea and ammonium sulfate, in natura cane and ensiled without any additive, in natura cane and ensiled with $1 \%$ of urea, in natura cane and ensiled with $8 \%$ of GEH (ground ears with husks) and in natura cane and ensiled with $0.5 \%$ of mineral salt). The concentration of DM of the sugar cane of the 11 months was, on average, $25.9 \%$ inferior to that at 24 months of age. The $\mathrm{pH}$ values did not range with the cutting ages but they differed between the treatments silage and in natura cane. The in natura cane added with $1 \%$ of the mixture urea + ammonium sulfate resulted into the best bromatologic values, the same occurring with the cane ensiled with urea, it being ,therefore, more convenient to ensile it than to leave it in the field for a further cultivation period. The ensiled material showed more elevated contents of CP, NDF and ADF.
\end{abstract}

Index terms: Cutting age, urea, ammonium sulfate, mineral.

(Recebido para publicação em 2 de março de 2005 e aprovado em 27 de dezembro de 2005)

\section{INTRODUÇÃO}

A cana-de-açúcar (Saccharum spp.) é uma cultura bastante difundida no Brasil (FARIA, 1993), sendo industrialmente utilizada para produção de açúcar e álcool. O País apresenta uma área plantada de 4.887 .647 hectares (AGRIANUAL, 2002) e produtividade média de 70 t/ha.

$\mathrm{O}$ uso da cana como forrageira durante o verão, caracteriza forragem de baixo valor nutritivo, contendo baixos teores de sacarose (MATSUOKA \& HOFFMANM, 1993). Além disso, o convívio com a dificuldade operacional de colheita no período chuvoso resulta na morte de plantas e problemas de manutenção do stand dos talhões. Diante do exposto, pode-se constatar que a ensilagem da cana constitui-se numa boa alternativa a esses problemas, uma vez que, pode ser a única forma de evitar perda total da forragem, em casos de incêndios acidentais ou intencional dos canaviais, além de facilitar a operacionalidade do seu manejo e utilização.

Quando é realizada a ensilagem da cana, concentra-se a mão-de-obra em apenas um período, com grande vantagem em relação às outras culturas utilizadas para a ensilagem, pois a cana está no ponto de corte na estação seca, facilitando o processo de ensilagem.

A cana-de-açúcar quando ensilada sem aditivos, apresenta fermentação alcoólica elevada e conseqüentemente produção de etanol, levando à limitação de consumo (NUSSIO et al., 2003).

\footnotetext{
${ }^{1}$ Parte da dissertação de Mestrado do primeiro autor.

${ }^{2}$ Zootecnista, M.Sc. em Zootecnia - Universidade Federal de Lavras/UFLA - Cx.P. 3037 - 37200-000 - Lavras, MG.

${ }^{3}$ Engenheiro Agrônomo, Dr. Professor do Departamento de Zootecnia da Universidade Federal de Lavras/UFLA - Cx.P. 3037 - $37200-000$ - Lavras, MG Bolsista do CNPq.

${ }^{4}$ Médico Veterinário, mestrando em Zootecnia - Universidade Federal de Lavras/UFLA - Cx.P. 3037 - $37200-000$ - Lavras, MG

${ }^{5}$ Engenheiro Agrônomo, M. Sc. em Zootecnia - Universidade Federal de Lavras/UFLA - Cx.P. 3037 - 37200-000 - Lavras, MG - ronan@ufla.br
} 
Em razão da grande demanda por informações sobre técnicas de conservação, mais especificamente sobre a ensilagem da cana-de-açúcar, objetivou-se, neste estudo, avaliar a composição química da cana-de-açúcar e das silagens tratadas com diferentes aditivos e colhida em duas idades de corte.

\section{MATERIAL E MÉTODOS}

O estudo foi conduzido no Departamento de Zootecnia da Universidade Federal de Lavras (UFLA), Lavras, MG, durante o período de junho 2002 a fevereiro de 2004. Nesse ensaio, em um esquema fatorial $2 \times 9$, foram testadas as influências de duas idades de corte da cana-de-açúcar (11 e 24 meses) e nove formas de utilização (cana picada acrescida de $1 \%$ da mistura uréia e sulfato de amônio na proporção 9:1, cana in natura e ensilada sem aditivo, cana in natura e ensilada com $1 \%$ de uréia, cana in natura e ensilada com $8 \%$ de MDPS e cana in natura e ensilada com $0,5 \%$ de sal mineral). $\mathrm{O}$ delineamento utilizado foi o inteiramente casualizado com três repetições. Para a primeira idade de corte, a cana foi cortada no dia 11 de outubro de 2002, 24 meses após o plantio, caracterizando cana planta bisada, evitando a permanência no campo por mais um período de crescimento, enquanto a segunda ocorreu no dia 11 de setembro de 2003, após 11 meses de rebrota, evitando-se que tornasse cana bisada. Os cortes foram realizados em um canavial estabelecido na Fazenda Cedro, localizada no município de Lavras-MG, sendo a variedade de cana-de-açúcar a RB-72.454. determinou-se o Brix em amostras representativas da cana por ocasião da colheita, utilizando refratômetro de campo. Para determinação do índice de maturação, levou-se em consideração a relação entre o Brix da ponta do colmo e o do colmo. Para confecção dos silos experimentais, foram utilizados canos de PVC com capacidade para aproximadamente $3 \mathrm{~kg}$ de silagem dotados de válvula do tipo "Bunsen". A cana foi picada em partículas de 2 a $5 \mathrm{~mm}$ em uma picadeira estacionária e, em seguida, foram aplicados os aditivos nas respectivas proporções. Para cana in natura, as amostras para realização das análises químicas, foram colhidas a partir do material previamente picado e misturado com os aditivos, tomando-se aproximadamente $800 \mathrm{~g}$ para os procedimentos laboratoriais e $50 \mathrm{~g}$ para determinação imediata do $\mathrm{pH}$. A compactação nos silos experimentais foi feita manualmente, com auxílio de barras de ferro. Ao final da compactação, os silos experimentais foram fechados e vedados com fita adesiva. Para as silagens, a amostragem foi realizada aos 60 dias após a ensilagem. $\mathrm{Na}$ coleta das amostras, foram desprezados os $5 \mathrm{~cm}$ das porções superior e inferior dos silos e, após esse procedimento, a silagem foi homogeneizada e, desta, extraída uma amostra de aproximadamente $800 \mathrm{~g}$ para as análises de laboratório e outra de $50 \mathrm{~g}$ para determinação imediata do $\mathrm{pH}$. As amostras da silagem e cana da in natura foram pré-secadas em estufa a $60^{\circ} \mathrm{C}$, por 72 horas, em seguida pesadas, moídas em moinho tipo Willey e armazenadas em potes plásticos devidamente identificados. Os teores de matéria seca (MS) e de proteína bruta (PB) foram determinados conforme métodos recomendados pela AOAC (1990). Os teores de fibras em detergente neutro e ácido (FDN e FDA) foram determinados segundo as técnicas descritas por Goering \& Soest (1970). As observações foram analisadas estatisticamente pelos procedimentos de análise de variância, por meio do programa estatístico SISVAR (Sistema de Análise de Variância para Dados Balanceados) (FERREIRA, 2000). Para efeito de comparação de médias entre tratamentos, foi utilizado o teste de Scott-Knott, a 5\% de probabilidade.

\section{RESULTADOS E DISCUSSÃO}

O teor de MS da cana-de-açúcar foi influenciado $(\mathrm{P}<0,01)$ pelas idades de corte, tratamentos e a interação entre eles. A cana-de-açúcar com 24 meses de idade, apresentou em média, teores mais elevados de MS $(30,14 \%)$ quando comparada à idade de 11 meses $(27,98 \%)$, conforme se verifica na Tabela 1.

Resultados semelhantes foram encontrados por Kung Junior \& Stanley (1982) e Silva (2003). Tanto para a cana in natura como para a silagem, o maior teor de MS observado foi para a cana aos 24 meses com 8\% de MDPS.

Apesar de um maior teor de MS da cana-de-açúcar aos 24 meses de idade, observou-se menores índices de maturação de $0,72 \%$ e $0,90 \%$ e teor de brix de $16,8 \%$ e $18,2 \%$, respectivamente para a cana com 24 e 11 meses de idade.

As silagens de cana-de-açúcar apresentaram menores valores de MS nas duas idades de corte, quando comparadas com a forragem não ensilada. Este fato possivelmente está relacionado à diminuição do conteúdo celular, principalmente de carboidratos solúveis, durante o processo fermentativo (WOOLFORD, 1984), perda de MS por meio de efluentes (MCDONALD et al., 1991) e gases (PEDROSO, 2003; SANTOS, 2004).

Os valores de $\mathrm{pH}$ foram influenciados pelas idades de corte $(\mathrm{P}<0,01)$, apenas para a silagem (Tabela 1$)$. Nas silagens, de maneira geral, o pH da cana cortada aos 24 meses de idade foi maior em relação à cortada aos 11 meses. Isto pode ter ocorrido em função do menor teor de carboidratos solúveis na cana-de-açúcar aos 24 meses. Pode-se perceber ainda a diferença $(\mathrm{P}<0,01)$ entre os valores de $\mathrm{pH}$ da cana antes e após a ensilagem, este fato decorre da conversão dos carboidratos solúveis a ácidos orgânicos que ocorre durante o processo fermentativo. 
TABELA 1 - Média dos teores de MS (\%) e pH da cana e da silagem com e sem aditivo em duas idades de corte.

\begin{tabular}{|c|c|c|c|c|c|c|}
\hline \multirow{3}{*}{ Tratamentos } & \multirow{2}{*}{\multicolumn{2}{|c|}{$\begin{array}{c}\text { MS } \\
\text { Idade (meses) }\end{array}$}} & \multicolumn{4}{|c|}{ pH } \\
\hline & & & \multirow{2}{*}{ Médias } & \multicolumn{2}{|c|}{ Idade (meses) } & \multirow{2}{*}{ Médias } \\
\hline & 11 & 24 & & 11 & 24 & \\
\hline Cana + uréia + SA & $29,56 \mathrm{cB}$ & $31,56 \mathrm{cA}$ & 30,56 & $5,36 \mathrm{aA}$ & $5,40 \mathrm{aA}$ & 5,38 \\
\hline Cana in natura & $29,29 \mathrm{~dB}$ & $31,47 \mathrm{cA}$ & 30,38 & $5,29 \mathrm{aA}$ & $5,27 \mathrm{aA}$ & 5,28 \\
\hline Cana + uréia & $29,30 \mathrm{~dB}$ & $31,61 \mathrm{cA}$ & 30,45 & $5,36 \mathrm{aA}$ & $5,36 \mathrm{aA}$ & 5,36 \\
\hline Cana + MDPS & $32,52 \mathrm{aB}$ & $34,01 \mathrm{aA}$ & 33,26 & $5,34 \mathrm{aA}$ & $5,53 \mathrm{aA}$ & 5,43 \\
\hline Cana + mineral & $30,64 \mathrm{bB}$ & $31,98 \mathrm{bA}$ & 31,31 & $5,46 \mathrm{aA}$ & $5,53 \mathrm{aA}$ & 5,49 \\
\hline Silagem de cana & $23,59 \mathrm{gB}$ & $27,63 \mathrm{gA}$ & 25,61 & $3,47 \mathrm{bB}$ & $4,25 \mathrm{bA}$ & 3,86 \\
\hline Silagem + uréia & $24,47 \mathrm{fB}$ & $28,54 \mathrm{fA}$ & 26,50 & $3,82 \mathrm{bA}$ & $3,78 \mathrm{bA}$ & 3,80 \\
\hline Silagem + MDPS & $27,96 \mathrm{eB}$ & $30,71 \mathrm{dA}$ & 29,33 & $3,32 \mathrm{bB}$ & $3,78 \mathrm{bA}$ & 3,55 \\
\hline Silagem + mineral & $24,50 \mathrm{fB}$ & $28,92 \mathrm{eA}$ & 26,71 & $3,32 \mathrm{bB}$ & $4,08 \mathrm{bA}$ & 3,70 \\
\hline Média & $27,98 \mathrm{~B}$ & $30,14 \mathrm{~A}$ & 29,35 & $4,53 \mathrm{~B}$ & $4,77 \mathrm{~A}$ & 4,65 \\
\hline
\end{tabular}

Médias seguidas de mesma letra minúscula na coluna e maiúscula na linha, para cada variável, não diferem entre si pelo teste de Scott-Knot $(\mathrm{P}<0,05)$.

Os valores de $\mathrm{pH}$ das silagens situam-se entre $3,32 \mathrm{a}$ 4,25 , ficando abaixo da faixa de 3,8 a 4,2 , recomendada por Silveira (1975) para a obtenção de silagem de boa qualidade. Molina et al. (2002), avaliando silagens com diferentes aditivos, encontraram variações no $\mathrm{pH}$ entre 3,22 e 4,19.

O teor de PB na MS da cana-de-açúcar foi alterado $(\mathrm{P}<0,01)$ pelas idades de corte, aditivos e interação entre eles. Na cana-de-açúcar com 11 meses, observaram-se teores mais elevados de proteína bruta na MS, em relação à idade de 24 meses (Tabela 2). $\mathrm{O}$ avanço do estádio de crescimento da cana-de-açúcar ocasionou um decréscimo nos teores de PB na MS. Kung Junior \& Stanley (1982), estudando o efeito do estádio de maturidade sobre o valor nutritivo da planta inteira de cana-de-açúcar com 24 meses, constataram menores teores de PB em comparação com idades mais jovens.

Os teores de PB na MS variaram entre 3,26\% para o tratamento cana de 24 meses in natura $+0,5 \%$ mineral e $14,37 \%$ para silagem de cana de 11 meses $+1 \%$ de uréia, sendo o valor mais alto justificado pelo incremento de nitrogênio da uréia à cana-de-açúcar. $\mathrm{O}$ fato da silagem com mesma proporção de uréia ter valor de proteína mais alto que a forragem, está ligado ao fato de que na forragem o material fica mais exposto ao ambiente, volatilizando a amônia em maior proporção do que na silagem. Castro Neto et al. (2003), avaliando silagens de cana-de-açúcar submetida a diferentes tratamentos, observaram efeitos semelhantes.
Observa-se uma superioridade dos teores de PB nos tratamentos ensilados sobre os tratamentos não ensilados, em ambas as idades de corte (Tabela 2). Na silagem de cana-de-açúcar observa-se um incremento de $21,38 \%$ e 22,51\% de PB na MS em relação à cana-de-açúcar in natura com 11 e 24 meses de idade, respectivamente.

Em consequiência da perda de carboidratos solúveis por respiração celular e processos fermentativos, a forragem fica com maior teor de componentes da parede celular, o que provoca efeito de concentração e aumento no percentual de PB na MS da silagem.

Para o teor de FDN na MS da cana-de-açúcar houve influência $(\mathrm{P}<0,01)$ das idades de corte, aditivos e interação entre eles. A cana-de-açúcar com 11 meses de idade apresentou menores teores de FDN na MS, quando comparada à idade de 24 meses, conforme se observa na Tabela 3, fato explicado pela lignificação dos tecidos e redução dos conteúdos celulares com o avanço da maturidade fisiológica das plantas (MERTENS, 1982).

Observa-se uma superioridade nos teores médios de FDN dos tratamentos com silagem de cana em relação aos tratamentos com material original (Tabela 3). Segundo Bernardes et al. (2002), tal fato ocorre, basicamente, por causa da redução nos teores de carboidratos solúveis no processo de fermentação alcoólica, acarretando aumento proporcional nos teores de constituintes de parede celular. 
TABELA 2 - Média dos teores de proteína bruta (\% MS) da forragem e da silagem de cana em duas idades de corte com e sem aditivo.

\begin{tabular}{lccc}
\hline \multicolumn{1}{c}{ Tratamento } & $\mathbf{1 1}$ meses & $\mathbf{2 4}$ meses & Média \\
\hline Cana + uréia + SA & $10,16 \mathrm{bA}$ & $7,46 \mathrm{cB}$ & 9,03 \\
Cana in natura & $4,08 \mathrm{eA}$ & $3,51 \mathrm{eA}$ & 3,79 \\
Cana + uréia & $9,75 \mathrm{bA}$ & $9,01 \mathrm{bA}$ & 9,38 \\
Cana + MDPS & $4,98 \mathrm{dA}$ & $3,95 \mathrm{eB}$ & 4,46 \\
Cana + mineral & $3,71 \mathrm{eA}$ & $3,26 \mathrm{eA}$ & 3,48 \\
\hline Silagem de cana & $5,19 \mathrm{dA}$ & $4,53 \mathrm{eA}$ & 4,69 \\
Silagem + uréia & $14,37 \mathrm{aA}$ & $10,47 \mathrm{aB}$ & 12,42 \\
Silagem + MDPS & $6,27 \mathrm{cA}$ & $5,40 \mathrm{dA}$ & 5,83 \\
Silagem + mineral & $5,45 \mathrm{dA}$ & $4,06 \mathrm{eB}$ & 4,39 \\
\hline Média $(\%)$ & $7,11 \mathrm{~A}$ & $5,62 \mathrm{~B}$ & 6,42 \\
\hline
\end{tabular}

Médias seguidas de mesma letra minúscula na coluna e maiúscula na linha não diferem entre si pelo teste de Scott-Knot $(\mathrm{P}<0,01)$.

TABELA 3 - Média dos teores de fibra em detergente neutro e ácido (\% MS) da forragem e silagem de cana com diferentes aditivos e duas idades de corte.

\begin{tabular}{lccccccc}
\hline \multirow{2}{*}{ Tratamentos } & \multicolumn{3}{c}{ FDN } & \multicolumn{3}{c}{ FDA } \\
\cline { 2 - 3 } & \multicolumn{2}{c}{ Idade (meses) } & & & \multicolumn{2}{c}{ Idade (meses) } & \multirow{2}{*}{ Médias } \\
\cline { 2 - 3 } \cline { 6 - 7 } & $\mathbf{1 1}$ & $\mathbf{2 4}$ & & $\mathbf{1 1}$ & $\mathbf{2 4}$ & \\
\hline Cana + uréia + SA & $47,28 \mathrm{eB}$ & $55,05 \mathrm{cA}$ & 51,16 & & $27,18 \mathrm{dA}$ & $35,85 \mathrm{cA}$ & 31,51 \\
Cana in natura & $48,60 \mathrm{eB}$ & $56,88 \mathrm{cA}$ & 52,74 & & $26,24 \mathrm{~dB}$ & $36,88 \mathrm{bcA}$ & 31,56 \\
Cana + uréia & $44,01 \mathrm{fB}$ & $52,74 \mathrm{dA}$ & 48,37 & & $26,54 \mathrm{~dB}$ & $35,57 \mathrm{cA}$ & 31,06 \\
Cana + MDPS & $47,37 \mathrm{eB}$ & $52,33 \mathrm{dA}$ & 49,85 & & $24,47 \mathrm{~dB}$ & $31,11 \mathrm{dA}$ & 27,79 \\
Cana + mineral & $46,96 \mathrm{eB}$ & $53,25 \mathrm{dA}$ & 50,10 & & $26,57 \mathrm{Db}$ & $35,44 \mathrm{cA}$ & 31,01 \\
\hline Silagem de cana & $69,87 \mathrm{aA}$ & $70,36 \mathrm{aA}$ & 70,11 & & $43,05 \mathrm{aA}$ & $43,31 \mathrm{aA}$ & 43,18 \\
Silagem + uréia & $66,21 \mathrm{bB}$ & $69,74 \mathrm{aA}$ & 67,97 & & $39,78 \mathrm{bB}$ & $42,94 \mathrm{aA}$ & 41,36 \\
Silagem + MDPS & $57,73 \mathrm{~dB}$ & $63,01 \mathrm{bA}$ & 60,37 & & $30,88 \mathrm{cB}$ & $36,44 \mathrm{cA}$ & 33,66 \\
Silagem + mineral & $63,40 \mathrm{cA}$ & $63,55 \mathrm{bA}$ & 63,47 & & $38,96 \mathrm{bA}$ & $39,21 \mathrm{bA}$ & 39,08 \\
\hline Média $(\%)$ & $54,60 \mathrm{~B}$ & $59,66 \mathrm{~A}$ & 57,13 & $31,52 \mathrm{~B}$ & $37,42 \mathrm{~A}$ & 34,47 \\
\hline
\end{tabular}

Médias seguidas de mesma letra minúscula na coluna e maiúscula na linha, para cada variável, não diferem entre si pelo teste de Scott-Knot $(\mathrm{P}<0,01)$.

Nos tratamentos com idade de corte de 11 meses ocorreram as maiores diferenças percentuais entre os grupos cana in natura vs silagens, podendo ser atribuída à maior quantidade de carboidratos solúveis perdida.

Os valores médios de FDN encontrados na cana antes de ensilar estão dentro dos padrões, conforme Soest
(1994), segundo o qual valores dos constituintes da parede celular superiores a 55-60\% na MS correlacionam-se negativamente com a ingestão e a digestibilidade da MS. Já os tratamentos do grupo silagem controle e aditivada apresentaram valores médios superiores ao proposto por Soest (1994), aos 11 e 24 meses, respectivamente. 
Pode-se observar, no grupo das silagens aditivadas que os tratamentos com $8 \%$ de MDPS aos 11 meses de idade de corte e com $8 \%$ de MDPS e $0,5 \%$ de mineral aos 24 meses de idade tiveram os menores valores médios de FDN (Tabela 3).

Coan et al. (2002), avaliando a composição química da cana-de-açúcar crua ou queimada ensilada com aditivo, concluíram que a ensilagem da cana fresca ou queimada resultou em aumento nos constituintes da parede celular e o uso do MDPS proporcionou silagens com menores valores desta fração.

Os teores de FDA na MS da cana-de-açúcar também foram influenciados $(\mathrm{P}<0,01)$ pelas idades de corte, aditivos e a interação entre eles. A cana-de-açúcar com 11 meses de idade apresentou menores teores de FDA na MS quando comparada à idade de 24 meses (Tabela 3). A fração FDA das forragens é constituída principalmente pelas frações celulose e lignina (SOEST, 1994) que vão aumentando com o avanço da idade das plantas. Valores aproximados aos da cana-de-açúcar in natura foram encontrados por Hernandez (1998), 30,4\%.

Analisando-se os teores de FDA da cana-de-açúcar ensilada em relação à cana-de-açúcar não ensilada, observa-se um incremento de $39,04 \%$ e $14,84 \%$ nas idades de 11 e 24 meses, respectivamente (Tabela 3).

De acordo com Alli et al. (1983), na ensilagem da cana-de-açúcar ocorre extensa atividade de leveduras, podendo estar presentes na ordem de $10^{6} \mathrm{UFC} / \mathrm{g}$ de forragem, que convertem os carboidratos solúveis da forragem a etanol, $\mathrm{CO}_{2}$ e água, resultando em perdas excessivas de MS, baixos teores de ácidos lático e acético e aumento no teor de FDA das silagens.

Em relação às silagens controle e às aditivadas, observou-se menores valores nas aditivadas, evidenciando-se uma ação favorável dos aditivos em relação ao teor de FDA. Molina et al. (2002), avaliando silagens de cana-de-açúcar tratadas com níveis entre $0,5 \%$ e 1,5\% de uréia, também encontraram teores mais baixos de FDA em comparação à silagem de cana exclusiva. Neste estudo, o menor valor de FDA nas silagens, foi observado com a cana aos 11 meses, aditivada com MDPS.

\section{CONCLUSÃO}

O tratamento cana in natura aos 11 meses adicionado com uréia ou uréia + sulfato de amônio proporcionou melhores valores bromatológicos, o mesmo ocorrendo com a silagem acrescida de uréia, sendo portanto mais conveniente ensilar a cana do que deixa-la no campo por mais um período de cultivo.

\section{REFERÊNCIAS BIBLIOGRÁFICAS}

AGRIANUAL. Cana-de-Açúcar. In: Anuário da agricultura brasileira. São Paulo, 2002. p. 249-273.

ALLI, I.; FAIRBAIRN, R.; BAKER, B. E.; GARCIA, G. The effects of ammonia on the fermentation of chopped sugarcane. Animal Feed Science and Technology, Amsterdam, v. 9, p. 291-299, 1983.

ASSOCIATION OF OFFICIAL ANALYTICAL CHEMISTIS. Official methods of analysis. 15. ed. Arlington, 1990. v. 1, 1117 p.

BERNARDES, T. F; SILVEIRA, R. N.; COAN, R. M. Características fermentativas e presença de leveduras na cana-de-açúcar crua ou queimada ensilada com aditivos. In: REUNIÃO ANUAL DA SOCIEDADE BRASILEIRA DE ZOOTECNIA, 39., 2002, Recife. Anais... Recife: SBZ, 2002. CD-ROM.

CASTRO NETO, A. G.; FERREIRA, D.; MOLINA, L.; GONÇALVES, L. C.; BORGES, I. NUNES, W. M. Avaliação de silagens de cana-de-açúcar submetidas a diferentes tratametos: II. proteína bruta, frações fibrosas e digestibilidade in vitro da matéria seca. In: REUNIÃO ANUAL DA SOCIEDADE BRASILEIRA DE ZOOTECNIA, 40., 2003, Santa Maria, RS. Anais... Santa Maria: SBZ, 2003. CD-ROM.

COAN, R. M.; SILVEIRA, R. N.; BERNARDES, T. F.; REIS, R. A.; MORENO, T. T. B.; MOREIRA, A. L. Composição química da cana-de-açúcar crua ou queimada ensilada com aditivo. In: REUNIÃO ANUAL DA SOCIEDADE BRASILEIRA DE ZOOTECNIA, 39., 2002, Recife. Anais... Recife: SBZ, 2002. CD-ROM.

FARIA, V. P. O uso da cana de açúcar para bovinos no Brasil. In: SIMPÓSIO SOBRE NUTRIÇÃO DE BOVINOS, 5., 1993, Piracicaba. Anais... Piracicaba: FEALQ, 1993 p. 1-16.

FERREIRA, D. F. SISVAR Sistema de análise de variância para dados balanceados. Lavras: UFLA, 2000.

GOERING, H. K.; SOEST, P. J. van. Forage fiber analysis: apparatus, reagents, procedures and some applications. Washington: USDA, 1970. 19 p. 
HERNANDEZ, M. R. Avaliação de variedades de cana-deaçúcar através de estudos de desempenho e digestibilidade aparente com bovinos. 1998. 78 f. Dissertação (Mestrado) Faculdade de Ciências Agrárias e Veterinárias de Jaboticabal, Universidade Estadual Paulista “Júlio de Mesquita Filho", Jaboticabal, 1998.

KUNG JUNIOR, L.; STANLEY, R. W. Effect of stage of maturity on the nutritive value of whole-plant sugarcane preserved as silage. Journal of Animal Science, Champaign, v. 54, p. 689-696, 1982.

MATSUOKA, S.; HOFFMANN, H. P. Variedades de canade-açúcar para bovinos. In: SIMPÓSIO SOBRE NUTRIÇÃO DE BOVINOS, 5., 1993, Piracicaba. Anais... Piracicaba: FEALQ, 1993. p. 17-35.

McDONALD, P.; HENDERSON, A. R.; HERON, S. The biochemistry of silage. 2. ed. Marlow: Chalcombe, 1991. 340 p.

MERTENS, D. R. Using neutral detergent fiber to formulate dairy rations. In: Proc. gainut conf. for the feed industry. Athens: University of Georgia, 1982. p. 116-126.

MOLINA, L. R.; FERREIRA, D. A.; GONÇALVES, L. C.; CASTRO NETO, A. G.; RODRIGUES, N. M. Padrão de fermentação da silagem de cana-de-açúcar (Saccharum officinarum L.) submetida a diferentes tratamentos. In: REUNIÃO ANUAL DA SOCIEDADE BRASILEIRA DE ZOOTECNIA, 39., 2002, Recife. Anais... Recife: SBZ, 2002. CD-ROM.
NUSSIO, L. G.; SCHMIDT, P.; PEDROSO, A. F. Silagem de cana-de-açucar. In: FORRAGICULTURA E PASTAGENS, TEMAS EM EVIDÊNCIA, SUSTENTABILIDADE, 4., 2003, Lavras. Anais... Lavras: UFLA, 2003. p. 49-74.

PEDROSO, A. F. Aditivos químicos, microbianos no controle de perdas e na qualidade de silagem de cana-deaçucar (Saccharum officinarum L.). 2003. 120 f. Tese (Doutorado) - Escola Superior de Agricultura Luiz de Queiroz, Piracicaba, 2003.

SANTOS, R. V. Silagem de cana-de-açucar em duas idades de corte com diferentes aditivos. 2004. Dissertação (Mestrado) - Universidade Federal de Lavras, Lavras, 2004.

SILVA, S. A. R. Avaliação da eficiência fermentativa da cana-de-açúcar ensilada com diferentes aditivos. 2003. 44 f. Dissertação (Mestrado em Zootecnia) - Universidade Federal de Goiás, Goiânia, 2003.

SILVEIRA, A. C. Técnicas para produção de silagem. In: SIMPÓSIO SOBRE MANEJO DE PASTAGEM, 2., 1975, Piracicaba. Anais... Piracicaba: ESALQ, 1975. p. 156-180.

SOEST, P. J. van. Nutritional ecology of the ruminant. 2. ed. Ithaca: Cornell University, 1994. 476 p.

WOOLFORD, M. K. The silage fermentation. New York: [s.n.], 1984. 305 p. 